\title{
The impact of climate change on the seismic vulnerability of the megalopolis of Almaty
}

\begin{abstract}
The largest city of Kazakhstan, Almaty, is located in the most seismically dangerous place in Eurasia. This article discusses the current issues of landslide risk in Almaty and the surrounding area because the potential risks have increased due to climate change and human activities. A cyclonic nature of these changes is suggested. They are believed to be global mechanisms of landslide activity. The impact of climate change on the seismic hazard of the region is assumed. The spatial-temporal and instrumental methods of landslide risk are assessed. The development of instrumental methods and accelerometers are suggested for the prevention of landslide and debris flow.
\end{abstract}

Volume 3 Issue I - 2019

Khaidarov Mukhtar

LLP Georisk, Republic of Kazakhstan, Kazakhstan

Correspondence: Khaidarov Mukhtar, LLP Georisk/ Republic of Kazakhstan, Kazakhstan, Tel 77077/43462,

Emailmkhaidarov@gmail.com

Received: January 10, 2019 | Published: February 05, 2019

Keywords: landslides, climate change, accelerometer, cyclone, risk, seismicity

\section{Introduction}

The scientific society has voiced their concern in light of recent climate changes in mountain areas. The city of Almaty is located in an alluvial cone of foothills of Zailiyskiy Alatau, a highly seismic zone of the Eurasian continent. The evaluation of consequences of such changes regarding global warming of atmosphere is necessary. One of the consequences we have observed is increased landslide activity caused by growing precipitation. This work offers strategies for landslide risk mitigation.

\section{Climate conditions of almaty}

In the 1960s, this was the classic situation: The western and northwest air masses bearing moisture, rose above mountainous areas and cooled down. Water vapor reached saturation points, and all that moisture was carried over the plains. The average annual precipitation amount of rainfall of $400 \mathrm{~mm}$ increased from the foothills to the middle of the mountains by 1.5 to 2 times, and in high mountain it was even more. Near permanent snow cover precipitation exceeded $1000 \mathrm{~mm}$, and in other years $1500 \mathrm{~mm}$. The climate was mild, yet extremely continental with dry, hot summers, and winters with snow and light freezing weather (Figure 1).

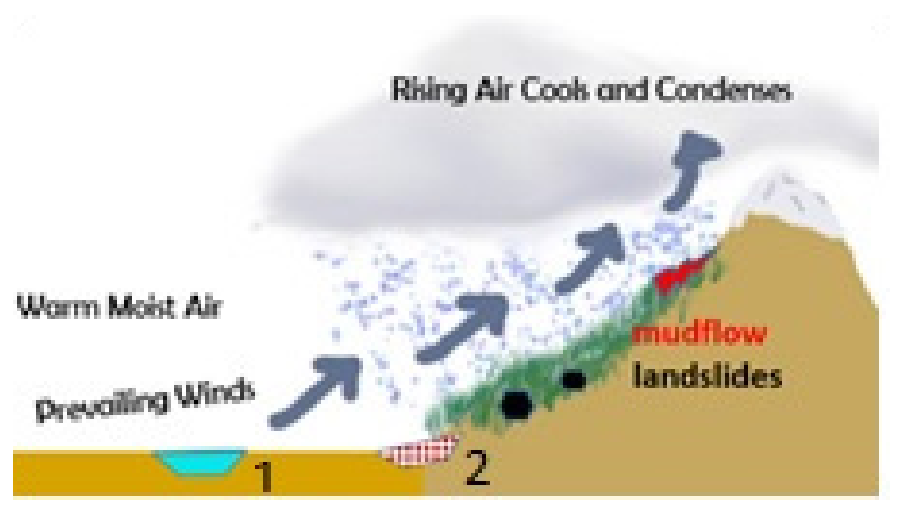

Figure I Almaty atmospheric and geophysical situation: mountain and valley winds, erosion processes.

Left to right: I, Kapchagai reservoir; 2, alluvial cone (Almaty); black spots, landslides; red, mudflow.
However, real shifts in the climate system can occur due to an accumulation of seemingly insignificant atmospheric changes. For example, we consider the Kapchagai reservoir. More than one cubic kilometer of water evaporates annually. Part of it rain down on Almaty. Waters of Kapchagai topped up low left bank became sort of support for ground water running down from Zailiyskiy Alatau. Due to the increased ground water level, marshes were formed. Marsh and salt accumulation caused additional evaporation and an increase of salt into the west and north with western winds carrying precipitation. As a result, in the 1970s, the climate of Almaty began to change (we'll call it "A") resulting in an increase of rainfall. We might say that the climate is now $\mathrm{C}+\mathrm{K}$ where $\mathrm{C}$ - classic, $\mathrm{K}$ - evaporation from warm Kapchagai reservoir with winds from the steppe. We have more rain now than in the 1960s. In addition to more rain, frost came early, and as a consequence we lost Oporto apples, a unique kind of apple of this area. ${ }^{2}$

Today 30 years later, we can add to this formula two more effects: global warming "G" and urbanization "U". A two fold increase of the population occurred in one generation, multiple new buildings were build, and the number of cars grew perhaps ten times. Thus, every day almost a million cars move in the city, with half of this number commuting to and from the city daily. Urbanization generates a lot of heat, water and pollution into the atmosphere. It is also important to note that $90 \%$ of the water used by the city is provided by drill holes and some of this water also gets into atmosphere. ${ }^{3}$

So, $\mathrm{A}=\mathrm{C}+\mathrm{G}+\mathrm{K}+\mathrm{U}$. Please note that every component in this equation contains water and warmth. Evidently, the last three components significantly change the situation. In the classical situation, condensation grew gradually with less amount of rain, and was balanced with change in the spring time. Local warming up from Kapchagai and urbanization of the city has led to the enlargement of the foot hill area, the city atmosphere and a drop in its pressure. This has caused a cyclonic effect and air is sucked. If it gets in from below, it carries the polluted and warm city from the steppe, which causes condensation. If the air comes from the top, it is cold and causes precipitation. It is called the piedmont - city cyclone. As evidence of this phenomenon, there is rain but on the 17th of May 2011, we experienced a unique hurricane at Medeo and Chymbulak site. Several thousand trees were destroyed. They were not carried by the force or broken with some exceptions, so the author believes 
that heavy air came down as a force and knocked the trees down. It happened unevenly due to relief or air currency. Therefore, the increase of precipitation and the massive loss of hilly forests could be an argument for beginning of an Almaty cyclone. Perhaps the cyclone may influence the glacier processes. A good cyclone provides solid precipitation. Consequences of this cyclone are evident. Rains are going to fill our hills causing hazardous conditions. Many people have noticed fresh landslides around the city. The risk of mudflow is real but to a lesser degree because of prevention steps that have been taken. Rain causes ground water to rise and has a negative effect on the environment.

\section{Climate change impact on region seismicity}

Seismicity situation deteriorates during major precipitation increase. The probability and scale of secondary consequences of earthquakes, such as landslides and mudflow, are growing. Massive and numerous landslides during an earthquake can lead to casualties and disrupt rescue operations. As well, the level of groundwater can reach the surface causing an increase in the force of the earthquake by 1 or 2 units. The Almaty area is already mapped as $8-9$ points by the MSK. We might reconsider seismic risk evaluation for Almaty. For example, this year a certain building in Almaty tilted by $32 \mathrm{sm}$. Some assume it was due to an increase of water caused by frequent rains. Earthquakes cause landslides. After the seismic impact, soil and rocks slide due to the shaking. For instance, even a small local earthquake with a magnitude of 2 will cause landslides. When strong earthquakes occur, landslides are a secondary result because of liquefaction (Figure 2).

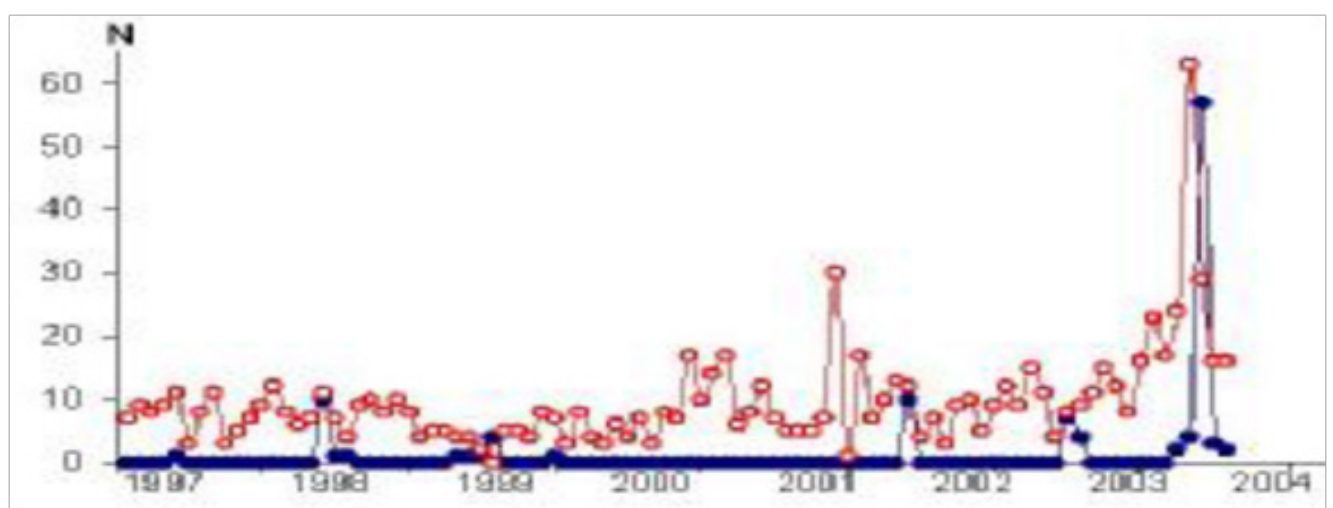

Figure 2 The number of weak earthquakes and landslides in the period from 1997 to 2004 in Almaty region. Red - the earthquakes, the blue - landslides. ${ }^{3}$

Research studies and specialists note that sometimes massive landslides occur across vast areas. The author witnessed this in 2004 while working for Kazselezashita (State Mudflow Defense Organization). The author connected these events with the Indonesian earthquake on December 26, 2004, which was rated as the deadliest disaster in modern history. It had a magnitude of 9.1 to 9.5 on the Richter scale. Before such strong earthquakes, we have observed the mitigation of seismic activity on the Earth. Several days before an earthquake, the world seismicity falls almost to zero. To confirm this, let's consider hydrogeological data from neighboring Kyrgyzstan which is located behind the mountain range of Zailiyskiy Alatau. "Clear synchronizing of ground water level of drill holes was noted for the period of 2001-2007 with a climax in 2003-2004. In those years, the maximum high level of ground waters and maximum enlargement of subsoil waterlogging of Chuyskaya basin". ${ }^{4}$ Calm zones of strong and medium earthquakes can reach massive areas, including several countries. Therefore, we can assume that global stress fields affect vast areas of the earth crust and can influence the levels of ground waters in vast areas. The last situation leads to landslides. For seismologists, the variation of ground water level is not unusual because the hydrodynamic way of forecasting earthquakes is to check for the variation of ground water in drill holes across large distances - up to $1000 \mathrm{~km}$ from the epicenter. Also, the correlation between current seismicity and irregularities of the Earth's rotation is interesting because it is occurring simultaneously with the rise the Earth's atmospheric temperature. It may be related to reasons of global warming and climate change. For instance, the 17 strongest earthquakes of $M \geq 8.5$ have occurred since 1900, and 6 of them happened in this century. ${ }^{5}$ Over a period of 12 years, $35 \%$ of them occurred and the last powerful earthquake was in 2012. It seems our planet is shifting. If this is so, our evaluation of risks has merit. Real cyclonic weather for Almaty, which was explained above, will continue in the future, and if certain steps are not be made, risks will increase.

\section{Methodology}

\section{Space methods of risks evaluation}

We know of few methods of landslide evaluation. The most popular is the mapping of possible landslides areas, and areas where landslides had taken place. Figure 3 is an example of a map for Central Asia and Caucasus completed by CFDRR in 2008. ${ }^{6}$ Figure 4 is a more detailed "Map of landslide capacity of northern slope of Zailiyskiy Alatau" which was published by the Geography Institute in Almaty in 2004.

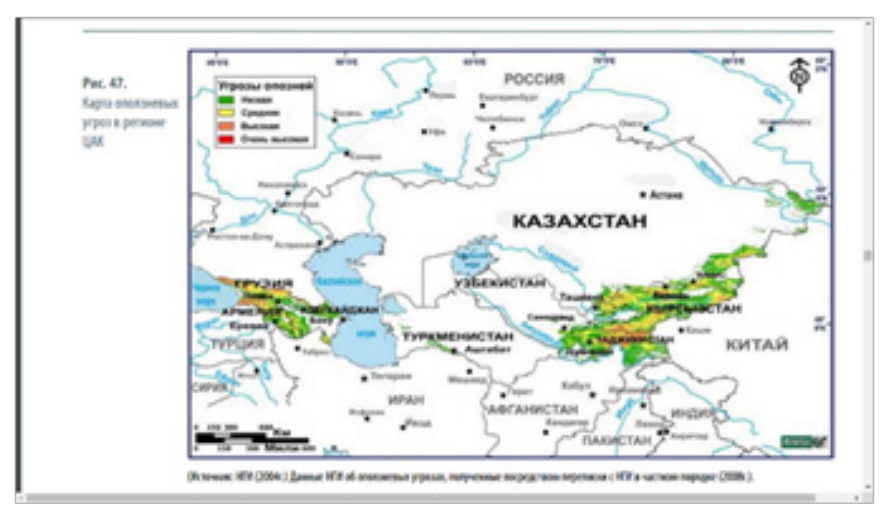

Figure 3 Map of landslide threats Central Asia and Caucasus region. 


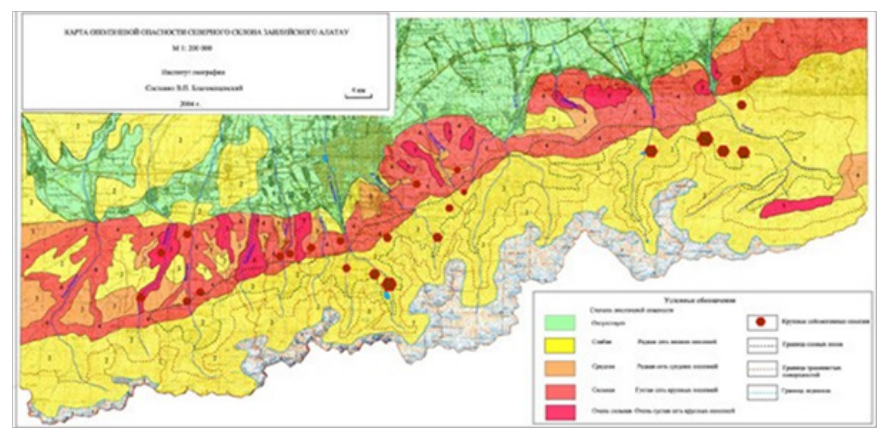

Figure 4 Landslide hazard map of the northern slope of the Zailiyskiy Alatau.

\section{Maps are in real time}

More information can be drawn from maps of real time from the Japan Meteorological Agency, for instance.

\section{Maps in real time are everywhere}

NASA freely offers a DRIP-SLIP program that allows landslides around the world to be tracked live.

\section{New field methods and results}

\section{Results of monitoring of field methods}

Russian specialists use field tools of monitoring and forecast as shown in Figure 5.

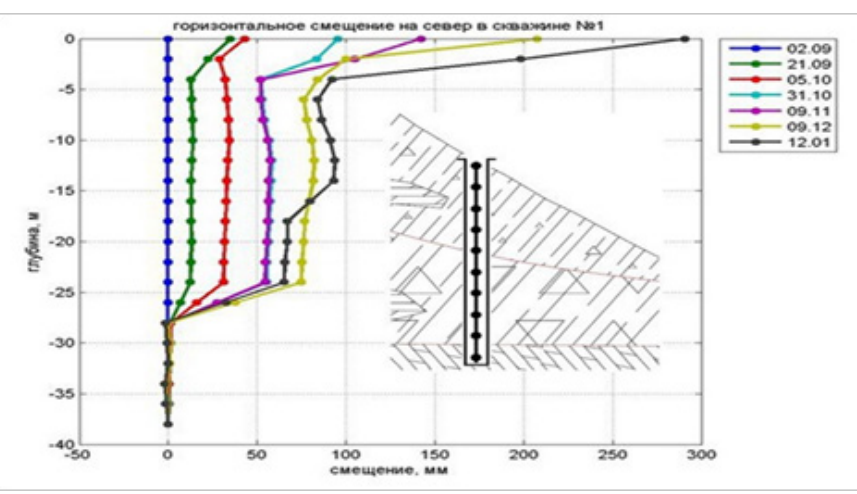

Figure 5 Horizontal displacement of landslides at different depths. Field scheme of mini sensors - inclinometers is displayed as vertical drill hole like sensors garlands. Seven diagrams created due to seven times fixation of inclination - dates of fixation are in right corner above. We can observe that in a period of 4.5 months, the upper layer of the landslide moved $30 \mathrm{sm}$.

\section{Use of accelerogram for monitoring of the process of erosion}

It would be more interesting to apply inclinometers but accelerographs as sensors not. Accelerographs contain more information about the tilt and acceleration. Tilts data allows us to track landslides and accelerograms track the mudflows. The use of inclination signals is shown in Figure 5. The use of accelerogram signals is shown in Figure 6.

As we can see Figure 6, the value of acceleration and hydrograph match. ${ }^{3}$ The record of mudflow acceleration is easily identified with records of close and distant earthquakes. Therefore, we see that implementing accelerographs is more useful because it allows to fixate both the landslides and mudflows in the seismic field. This is useful as we can observe landslides and mudflows occurring in one space temporal area. At the same time, it allows us to see the erosion processes, landfall, rock fall, as well as the earthquake seismic activity. Also, the accelerograph is a popular and cheap sensor. Once it is in the soil, it doesn't require maintenance. It can also be useful for detecting earthquakes.

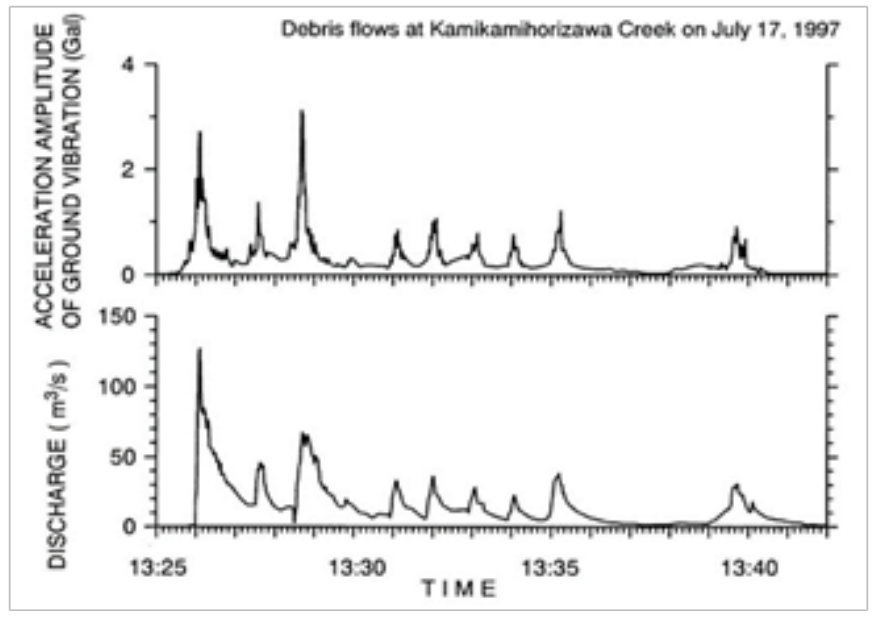

Figure 6 Record accelerations and hydrograph made by Japanese specialists.

\section{Record of Almaty landslide process}

It is very important to know which records to analyze. We were able to get records of landslides near the Talgar seismic station near Almaty. ${ }^{3}$ This is a record of velocity of displacement, and it is not too different from the acceleration in Figure 7. It is important to note the Main low frequency channels - 0.6 and $1.25 \mathrm{~Hz}$. We can interpret the first group of waves as mild loss of stability - the analog of such instability is shown in the right upper corner. The second lower amplitude group of waves can be interpreted as an impact of a main landslide mass onto the surface. The impact is seen on high frequency channels. The author participated in research of this medium sized landslide. It was a vertical landslide of some tens of meters. Knowledge of such signals can help identify landslide fulfillment especially after preliminary monitoring of tilts signals. It will help the emergency services process. The amplitude of landslides records quickly attenuate with distance as shown in Figure 8. ${ }^{7}$

\section{Examples of field sensors}

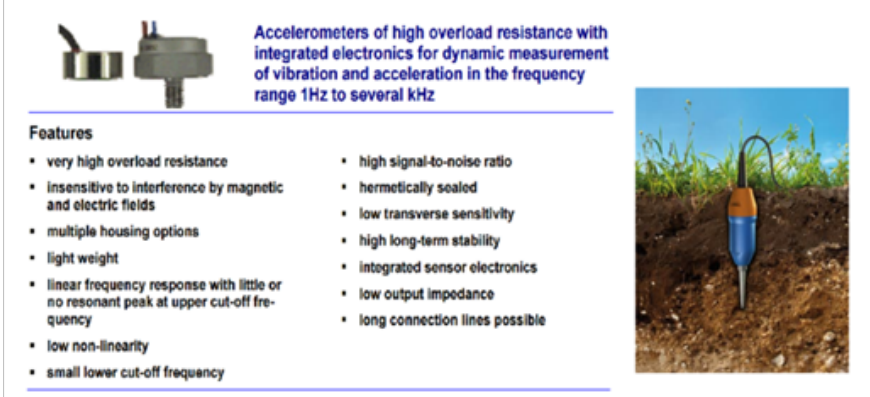

Figure 7A Example of compact accelerometer (left) and its installation into the soil (right). Modern microelectronic systems allow for the small size and low power consumption. On the right, we see its field use in a rugged case, inside of which is a battery, two axis accelerometers and a GSM transmitter.

For monitoring mudflows which also quickly attenuate, it would be appropriate to install sensors along mudflow prone river banks, several meters away from river. Of course, installation issues are 
resolved on the spot and based on the task. Therefore, to successfully monitor hundreds of hazardous mudflow or landslide spots and activity, it is best to use accelerometers. They allow us to receive two signals simultaneously: tilts of upper layer of ground where sensor is installed and acceleration that shows us of more energetic processes of mudflows.

Seismic record landslide in the foothills of Almaty, on channels with filters $0.6,1.25,2.5,5.0,10.0 \mathrm{~Hz}$

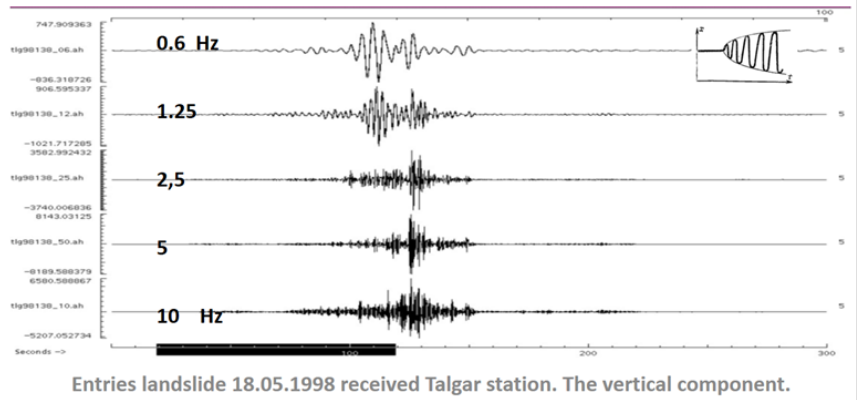

Figure 7B Seismic record landslide near Almaty. ${ }^{3}$

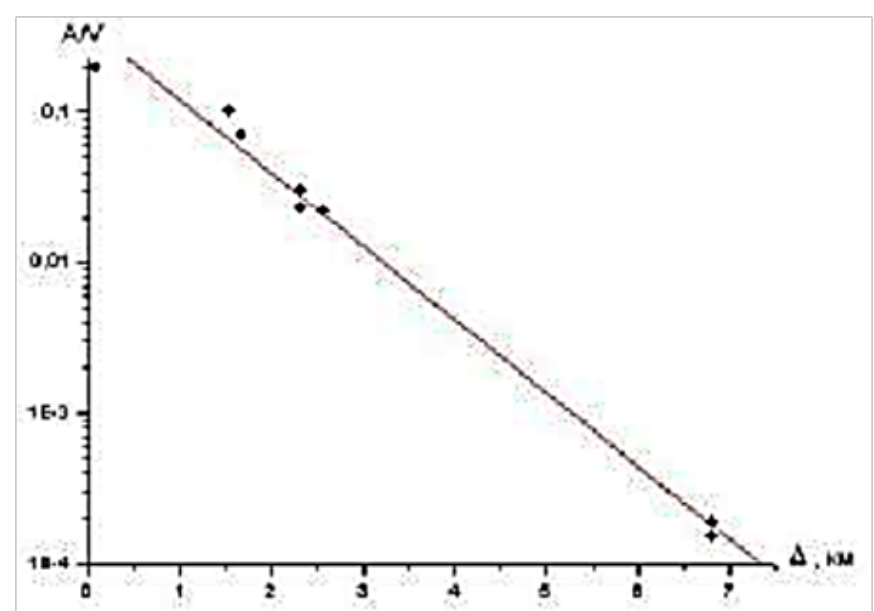

Figure 8 Attenuation landslide amplitude seismic records (normalized to the volume of the landslide) with distance.

\section{Discussion}

Discussions in this work is inevitable and necessary especially with meteorologists. We offer our geophysical approach. Discussion could be voiced over the development of Almaty cyclone formation. We can only refer to the facts such as increased rain fall, strong winds and the loss of mountain forests. Regarding landslide mitigation steps, there two large if not grandiose measures that could be taken. Firstly, there has to be scientific ground for emptying the Kapchagai water reservoir. It is clear that reason for the increase in rainfall is global warming, but the water reservoir also has a huge impact. The water reservoir is under our control, but global warming is not. Secondly, there has to be grounded reasons for curbing the urbanization of Almaty. Clearly there will be social implications, but the climate of the foothills is sensitive to water flow, increased temperatures and pollution. Interested stakeholders in Almaty have held talks on this matter, but not much progress was made. However, we could at least start with banning older vehicles which discharge a high concentration of pollution because of worn out engines. Field methods can have other characteristics. By suggesting the use of accelerographs, we can gather a lot of information at a low price. That will allow us to quickly create a local monitoring network. We can use GSM and each spot as a WAP. The type of communication could be different, but what is essential is that the sensor data should be available on the Internet. One weak aspect could be GSM, but when using several sensors, the connection can be clearer. Clearly, the use of sensors is not scientifically accurate, but the sake of safety, it is quite acceptable. The basis of this work was completed in the summer of 2016. Our fears of an increase in landslide hazard were confirmed in the spring of 2018 - Christoph Grützner 21.04.18 reported: "A large landslide occurred in Kazakhstan... The slide is about 900 m It's widespread, it's $1700 \mathrm{~m}$ long and it's estimated at $50,000,000 \mathrm{~m}^{3} \ldots$ (http:// paleoseismicity.org/large-landslide -in-the-epicentral-area-of-the1889-chilik-m8-earthquake-kazakhstan /). It should be noted that the first motions of this tremendous landslide began at least on April 18, judging by the records of the increased seismic background at the near seismic station Saty. We agree that the main cause was a high rainfall intensity, but we note that on April 8 an earthquake with a magnitude of $m p v=4.8\left(42.96^{\circ} \mathrm{N}, 78.29^{\circ} \mathrm{E}, \mathrm{H}=10 \mathrm{~km}\right)$ with an intensity of $\geq 3$ on the MSK64 scale, which could trigger the descent landslide. There were no other earthquakes in the vicinity. It was the largest landslide in half a century on the northern slopes of the Northern Tien Shan.

\section{Conclusion}

a. The climate of Almaty has changed, with the formation of a cyclone. Change has happened and increased rainfall and strong winds are evident especially in Almaty where in early years (the 1960s and 1970s) still days were the norm. We interpreted these changes, the Almaty cyclone, are due to global warming, manmade influence of the Kapchagai water reservoir and rapid urbanization.

b. Number of landslides and mudflow has increased. If we are right about Almaty mountainous cyclone, we are faced with an increased risk of landslide and their hazards. The level of mudflow will lift as well because landslides and mudflows boost each other and often share one origin.

c. Seismic hazards will increase, expressed in seismo-landslides and seismo-mudflows, and the level of earthquake intensity will increase due to the higher level of ground water. All this will lead to increased vulnerability of Almity city and its suburbs

d. There may be wider ranging environmental impact.

\section{Recommendations}

i. Create an international pool of scientific hydrogeologists, geophysicists, ecologists, economists, and others to support the shutdown of the Kapchagai reservoir.

ii. Develop a set of measures to limit urbanization.

iii. Carry out work on the draining of dangerous sites and important facilities.

iv. Develop and implement a monitoring and warning system for dangerous landslides and mudflows in an electronic online mode.

\section{Acknowledgments}

None.

\section{Conflicts of interest}

The author declares that there is no conflicts of interest. 


\section{References}

1. Kochkarova DT. The climate of Kazakhstan and the trend of change. Scientific work on the geography of the RK Ministry of Education and Science. 2014

2. Marikovskii PI. Balkhash threatens the fate of the Aral Sea. 2007.

3. Khaidarov MS. Methods and prospects of monitoring landslides. $G U$ “KazSeleZashshita” report in Russian, Almaty. 2014.

4. Erokhin SA, Bidenko ZS, Zaguinay VV, et al. Methods of predicting flooding process and the possibilities of its revitalization in 2014 in the intermountain basins of Northern Kyrgyzstan, Part III. Research and development in the field of monitoring and forecasting of emergency situations. 2014.

5. Largest Earthquakes in the World Since 1900. USGS.

6. Risk Management Initiative disasters in Central Asia and Caucasus. Disaster Risk Assessment Summary Report Central Asia and the Caucasus. 2015.

7. Khaidarov MS. Technical expert report on the theme: Development of the concept of creation of automated information Natural Disaster Monitoring Systems. United Nations Development Programme in Kazakhstan in 2013, in Russian. 2013. 